\title{
How Literacy Acquisition Affects the Illiterate Mind - A Critical Examination of Theories and Evidence
}

\author{
Falk Huettig ${ }^{1,2 *}$ and Ramesh K. Mishra ${ }^{3}$ \\ ${ }^{1}$ Max Planck Institute for Psycholinguistics \\ ${ }^{2}$ Donders Institute for Brain, Cognition and Behaviour, Radboud University \\ ${ }^{3}$ Centre for Neural and Cognitive Sciences, University of Hyderabad
}

\begin{abstract}
At present, more than one-fifth of humanity is unable to read and write. We critically examine experimental evidence and theories of how (il)literacy affects the human mind. In our discussion, we show that literacy has significant cognitive consequences that go beyond the processing of written words and sentences. Thus, cultural inventions such as reading shape general cognitive processing in non-trivial ways. We suggest that this has important implications for educational policy and guidance and research into cognitive processing and brain functioning.
\end{abstract}

\section{Introduction}

Adult illiteracy, the inability to 'both read and write a short simple statement on his (her) everyday life' (UNESCO, 2008) remains a tangible problem despite rapid socio-economic development across the world. More than one billion people, one in five humans, are currently illiterate. On the one hand, there is little doubt that progress towards eradicating illiteracy has been made. The literacy rate of India, for example, was at $12 \%$ when the country became independent from British rule in 1947, whereas, according to the last census taken in 2011, it has now risen to $74 \%$. On the other hand, it means that even today, one in four Indians cannot read and write. India is not unusual in this regard. For some of India's neighbors, the figures are even worse: one in two persons in Nepal and Bangladesh and one in three people in Pakistan are illiterate, while similar figures can also be observed in many African nations.

An important aim of this review is to highlight the cognitive consequences of (il)literacy. A thorough understanding of the impact of literacy on the human mind is an essential prerequisite for successful education policy and guidance of didactic support. A second aim is to spell out the implications of research into the cognitive consequences of literacy acquisition on mechanisms of perception, attention, memory, spoken language processing, and other cognitive systems. In other words, researchers have long been interested in the consequences of literacy on cognitive processes other than reading per se. Effects of literacy provide important clues for our understanding of the functioning of key parts of cognition and of brain plasticity, i.e., key interests of cognitive psychology and cognitive neuroscience.

\section{Historical background}

Writing, a human cultural invention, is on an evolutionary scale a very recent occurrence. The Sumerian script in Mesopotamia, typically considered the first writing system, was developed only 5500 years ago. Many scripts across the world developed independently (e.g., Indus valley script, Chinese script, and Maya script) and their history is complex. Most scripts can be traced 
back to pictographic writing. Pictographic writing systems such as Chinese require a very large number of symbols, and few Chinese speakers are able to write all the spoken words they can understand. Syllabaries (e.g., the Japanese Katakana) are writing systems in which each character represents a consonant and the following vowel (e.g., ka, ke, and ki). Note that many writing systems are hybrid systems. Japanese writing, for instance, is a mixture of a syllabary and Chinese characters. Alphasyllabaries (or 'syllabic alphabets') such as the Indian Devanagari represent consonant and vowel sounds (with vowel sounds represented with diacritics, i.e., modifiers to the consonant symbols). All modern alphabetic writing systems can be traced back to the Semitic alphabet which was developed around 3500 years ago. Some alphabetic writing systems (e.g., Arabic, Hebrew) have no characters for vowels. In Hebrew, little dots and dashes above and below the characters are sometimes added to help young children or other less proficient Hebrew readers learn to read Hebrew. The ancient Greeks further developed alphabetic writing systems by adding characters for vowels.

There have been some discussions whether there is an optimal writing system for a given language (e.g., Rogers, 1995). All writing systems have advantages and disadvantages. A syllabary, for instance, may require less writing and fewer character identifications than an alphabetic system. The alphabetic system has often (mostly in the West) been regarded as a superior writing system (e.g., responsible for the intellectual dominance of Greek culture over other ancient cultures, Havelock 1976). Though many have speculated that alphabetic systems give rise to an intellectual advantage (e.g., Ong, 1982), there is no experimental evidence to support such a claim. It is however important to keep the differences among writing systems in mind when drawing conclusions about the influence of literacy on cognition.

Until quite recently, literacy has been restricted across the world to specific minority groups. Literacy was largely a preserve of the wealthy who could afford a formal higher education and the clergy. Even as recent as 1870, for example, $80 \%$ of the African American US population was illiterate (even though illiterates only represented $20 \%$ of the entire US population at that time). In France, approximately $60 \%$ of the population was illiterate in 1740 , but by 1880 , the illiteracy rate had fallen to less than 10\%. In England, 1840 , about $40 \%$ of people still signed their marriage certificate with their 'mark' (usually an X or some other personalized sign) because they could not write. Thus, until very recent times and throughout most of human history, cognitive processing was not influenced by processing and/or knowledge of written language.

Since the first writing systems appeared, many scholars have theorized about the impact of reading and writing on human cognition and society at large. Plato considered writing an inhuman, alien technology which weakens the mind and has detrimental effects on memory (see Ong, 1982, for further discussion).

In contrast, Havelock (1963) argued that literacy led to explicit definitions of terms and logical analysis and by extension modern society. Goody and Watt (1968) argued that writing preserves what is said and thereby facilitates critical debate and thinking. McLuhan (1962) suggested that Gutenberg's invention of the printing press led to a shift from oral to silent reading resulting in a more fundamental separation of spoken and written language. Similarly, Ong (1982) argued that writing transforms spoken language into an object of thought and reflection (a view also promoted by Vygotsky, 1978).

The idea that literacy is inevitably beneficial and that high literacy rates are characteristic of highly developed societies has itself been questioned. Pattanayak (1991), for instance, suggested that literacy is an instrument of Western oppression and arrogance. This view has also been taken by some Western scholars such as Levi-Strauss (1961) who argued that 'the primary purpose of writing, as a means of communication, is to facilitate the enslavement of other human beings' (p. 292).

Finally, Olson (1994) pointed out: 
Our beliefs about literacy are a blend of fact and supposition, in a word a mythology, a selective way of viewing the facts that not only justifies the advantages of the literate but also assigns the failing of the society, indeed the world, to the illiterate (p. 2).

In sum, many scholars have theorized about how literacy acquisition affects the illiterate mind, much less work however has focused on providing experimental data supporting or refuting particular theoretical claims. Theories in absence of experimental evidence unfortunately amount to little more than speculation (cf. Popper, 2002). The purpose of the present review is to assess the existing body of research that has examined the effects of literacy on cognition.

In this article, we shall focus on investigations of adult (il)literacy. Another useful way to assess the influence of literacy acquisition on cognitive processing is to observe children as they learn to read. A disadvantage of this approach is that influences of child and brain development (e.g., influences of developmental brain plasticity and critical periods) cannot easily be separated from general influences of literacy. We emphasize however that we do not negate the important conclusions that can be drawn from developmental research.

Note also that the terms 'literacy', 'literates', and 'illiterates' are used in many different (and not always compatible) ways. Not long ago anybody who could merely write his or her name was considered to be literate (Breivik, 1991). Our review is not concerned with people who are often termed 'functional illiterates' in the West, typically defined as 'a person with some basic education who stills falls short of a minimum standard of literacy or whose reading and writing skills are inadequate to everyday needs' (Random House Kermerman Webster's College Dictionary, 2010). In other words, functional illiterates are persons who received some education and have some basic reading knowledge but who cannot read or write well enough to fulfill the requirements of a literate society. Functional illiteracy can be due to a great variety of reasons ranging from neurological and cognitive deficits to social problems which impeded adequate literacy acquisition. In the present review, we evaluate research conducted on persons who have no known neurological deficits yet have either a very limited or no ability to read and write due to an absence of (henceforth 'illiterates') or very limited (henceforth 'low literates') exposure to reading instruction.

\section{Experimental participants}

Before we can assess the quality of evidence for effects of literacy acquisition on the illiterate mind, it is important to consider the characteristics of the participant populations used in the respective studies. Note in this regard that we consider experimental studies with control groups embedded within the same culture as providing the most crucial evidence. Comparisons between literate and oral cultures will always be prone to criticisms that observed differences were due to culture-specific rather than literacy-specific factors (e.g., the classical studies of Lévi-Bruhl, 1923; McLuhan, 1962; Goody \& Watt, 1968; Ong, 1982). Here, we describe briefly the background of participants in key experimental research programs.

\section{I. UZBEKISTAN AND KIRGHIZIA}

The great Russian psychologist Alexander Luria, on the advice of another great Russian psychologist, Lev Vygotsky, conducted large observational studies on illiterates in Uzbekistan and Kirghizia in 1931-1932. Luria (1976) was the first to study cognitive processing in illiterates in a systematic way. He compared performance of five different participant groups. Two of the groups (which he defined as illiterate traditional women from remote villages and illiterate peasants from remote villages) he did not consider to be exposed to modern ways because they were not involved in the Soviet collectivization of agriculture which took place at the time. The three 
other groups which he considered to be in contact with modern ways of life were low literate women with some experience of training nursery school teachers, collective farm workers with low literacy skills, and moderately literate school teachers.

3.2. LIBERIA

In more recent years, Scribner and Cole (1981) studied a small West African group, the Vai people, who had developed their own writing system. Importantly, many of the Vai script literates never attended formal schooling. Other Qur'anic-learning Vai people only learned to read the Arabic script. This allowed Scribner and Cole to compare Vai illiterates with Vai script literates, those who had gone to school and those who had not, together with Arabic script literates.

3.3. PORTUGAL

Most experimental studies have been conducted with Portuguese illiterates. Morais and collaborators (e.g., Morais, Cary, Alegria, \& Bertelson, 1979) conducted extensive research with illiterate and ex-illiterate peasants from poor agricultural areas in Portugal or illiterate individuals from Lisbon shanty towns. Most of these participants were elderly women. Reis, Petersson, Castro-Caldas, and colleagues have repeatedly tested a participant pool of illiterate women from the fishing village of Olhão in the Algarve region of Portugal. These illiterate women were typically older daughters who stayed at home to help with the upbringing of younger siblings. As a consequence, they did not receive any formal schooling. Reis, Guerreiro, and Petersson (2003) provide an extensive discussion of the characteristics of this participant population.

3.4. GREECE

Kosmidis and colleagues (e.g., Kosmidis, Tsapkini, Folia, Vlahou, \& Kiosseoglou, 2004) tested also mostly elderly illiterate women (mean age 72 years) from a poor agricultural society in Greece. These women had not attended school for socioeconomic reasons.

\subsection{COLUMBIA AND BRAZIL}

Two recent imaging studies used South American participants. The 22 illiterates (11 males, 11 females; mean age 32.8 years) that participated in the structural imagining study conducted by Carreiras, Seghier, Baquero, Estévez, Lozano, Devlin, and Price (2009) were members of Colombian guerrilla forces who had put down their weapons or house wives from a similar socioeconomic background. Dehaene, Pegado, Braga, Ventura, Filho, Jobert, Dehaene-Lambertz, Kolinsky, Morais, and Cohen (2010) scanned 10 illiterates, 22 ex-illiterates, and 31 schooled and literate adults from rural and suburban areas of Brazil (and also Portugal).

\subsection{INDIA}

Huettig and Mishra have been conducting experimental behavioral and neuroimaging studies with illiterate and low literate participants in India. Low literate participants are mostly young adults from Allahabad in the northern Indian state of Uttar Pradesh (e.g., Huettig, Singh, \& Mishra, 2011). Illiterate (and literate control) participants are young adults from the same (Dalit) community from two villages near Lucknow (Huettig, Mishra, Kumar, Singh, Guleria, \& Tripathi, in preparation). Illiteracy and low literacy levels in Uttar Pradesh are mainly due to 
no or very little formal schooling as a result of poverty and other socioeconomic factors, rather than deficiencies in individual social or cognitive abilities.

\section{Effects of literacy vs. schooling}

Another important question which it is important to discuss at the outset of this article is whether particular experimental effects and cognitive abilities are due to literacy or are more general effects of schooling. Scribner and Cole (1981) argued that it is possible to draw a strict distinction between literacy and schooling. As mentioned above, Scribner and Cole compared Vai script literates who never attended formal schooling with illiterates. They argued that:

The existence of an indigenous script, transmitted outside of an institutional setting and having no connection with a Western-style school, would make it possible for us to disentangle literacy effects from school effects (p. 19).

They also criticized that:

Many writers discuss literacy and its social and psychological implications as though literacy entails the same knowledge and skills whenever people read or write, our experimental outcomes support our social analysis in demonstrating that literacies are highly differentiated (p. 132).

Note in this regard however that Scribner and Cole based their conclusions in part on their results with the Vai script which is quite different from many modern scripts and may well be similar to early human writing systems (e.g., Egyptian hieroglyphics): the reader can decipher the message the writer intended only roughly (Ong, 1982).

Most scholars have rejected the suggestion that it is possible to draw a strict distinction between literacy and schooling. Olson (1994) argued that:

Literacy is not just a basic set of mental skills isolated from everything else. It is the evolution of those resources in conjunction with the knowledge and skill to exploit those resources for particular purposes that makes up literacy (p. 43).

Schooling is a literate institution, and to study the effect of literacy, one cannot separate it from its various institutional contexts (cf. Goody, 1987). Moreover, all forms of reading instruction involve aspects associated with formal schooling. In other words, it is very unlikely that teaching of the Vai script to Vai people outside of formal schools is completely different from forms of instruction in school settings. We conjecture that isolating the distinction between effects of literacy and effects of schooling is unattainable. Scribner and Cole are undoubtedly right however that literacy-on-cognition effects will be influenced by the particular properties of the script(s) a literate individual has learned. We will now turn to the discussion of key studies and their implications.

\section{Perception}

\section{I. AUDITORY PERCEPTION}

We are aware of only two studies on auditory low level perceptual processing in illiterates. Serniclaes, Ventura, Morais, and Kolinsky (2005) investigated categorical perception in illiterates using $/ \mathrm{ba} /-/ \mathrm{da} /$ contrasts. Categorical perception refers to the phenomenon that changes in (for example) a sound along a continuum are perceived not as continuous but as instances 
of discrete categories. In a typical experiment, synthetic syllables are presented in which the second formant is modified systematically in equal steps. Participants tend to report that they perceived the resulting sounds as /ba/, /da/, or /ga/. Serniclaes et al. (2005) found very similar performance of illiterates and literates with this task. The only difference observed was that illiterates showed a less precise categorical boundary and a stronger lexical bias. Lexical information can bias categorization of ambiguous speech sounds. In Portuguese, the syllable /ba/ is a non-word. The syllable / da/ on the other hand is a frequent word translating as 'give me'. Thus, illiterates' categorical perception was found to be similar to literates, but their responses showed more of an influence of the knowledge of existing words.

Morais and colleagues have also reported similar performance between illiterates and literates for the McGurk effect (Morais, Castro, \& Kolinsky, 1991). The McGurk effect refers to an auditory illusion in which participants hear a syllable such as /ba/ and see simultaneously a person's visual lip-movements saying / ga/. In the study, both literates and illiterates as is typically found reported that the person said /da/. In short, these studies suggest that low level speech perception abilities in low literates are largely intact. However, given the small number of studies on auditory perception, this conclusion should perhaps be considered tentative.

\subsection{VISUAL PERCEPTION}

Luria's (1976) work has been quite influential but controversial and thus merits some more extended discussion. Luria considered his (often cited) observations on visual illusions in illiterates as one of his most important findings. He followed up on research by Rivers (1905) who had claimed that the Toda people in India were susceptible to fewer optical illusions than Europeans. Luria (1976) presented nine optical illusions to his participants in Uzbekistan (including the Múller-Lyer illusion, the Poggendorff illusion, the Necker cube, and the Mach book). Illiterates spotted much fewer illusions than literates. He was so excited about his findings that he sent a telegram to Vygotsky stating 'The Uzbekis have no illusions' (Nell, 1999). ${ }^{1}$ In his 1976, book Luria concluded:

Optical illusions are not universal. The number of illusions fluctuated strongly, increasing to $75.6 \%$ as the educational level of the subjects rose... thus the data clearly show that optical illusions are linked to complex psychological processes that vary in accordance with socio-historical development...we can readily distinguish specific geometrical structures that yield a high percentage of illusions among subjects with a higher educational level but that give rise to no such illusions among illiterate subjects (p. 43).

Luria's description however lacks detail; for instance, it is unclear how he actually phrased the question about the illusions to his participants. Moreover, recent historical work by Russian scholars raises further doubts regarding these results. Allik (2013) suggests that Luria published these results only 40 years later because Luria and Koffka (the famous Gestalt psychologist) did not agree about the observations about visual illusions. Koffka had joined Luria on his expedition and was in fact in charge of conducting the experiments on visual illusions. Allik (2013) writes that Luria 'was too eager to find proofs that social-cultural practices shape almost every aspect of human mind’ (p. 40). Similarly, Lamdan (2013) concludes:

Luria's experimental data on optical illusions does not hold water. The picture is not entirely clear, but it is obvious that both theoretical and ideological assumptions and specific scientific approach influenced Luria's attitude to the data obtained during the second expedition. Apparently, this attitude was the reason that the participation of Koffka in the expedition and the disagreements with him were glossed over, and why we received, many years later, a not entirely quite accurate version of the study (p. 75). 
Indeed, there is a 1934 paper in which Luria himself stated: 'With very few exceptions the men and women examined by us succumbed to the optical illusions - of which a great variety was shown- just as we do' (p. 257).

It is also noteworthy that Luria's optical illusions were line drawings. Reis, Petersson, CastroCaldas and Ingvar (2001) have provided some data which suggests that illiterates perform poorer than literates when naming line drawings. There was no difference between illiterates and literates when naming real (3D) objects. In a follow-up study, Reis, Faisca, Ingvar, and Petersson (2006) observed that if color was present, naming accuracy in illiterates increased independent of presentation mode (i.e., line drawing or photograph). Furthermore, when color was present, object naming accuracy between illiterates and literates was similar. These results suggest that formal schooling facilitates rapid identification of (black and white) 2D visual objects.

Some recent work has looked at how literacy affects mirror image contrasts. Learning an alphabetic script, for instance, involves paying attention to mirror image contrasts such as distinguishing ' $b$ ' from 'd'. Kolinsky, Verhaege, Fernandes, Mengarda, Grimm-Cabral, and Morais (2011) found that illiterates have problems with lateral mirror images. Illiterates performed well when only orientation was varied, but when other stimulus characteristics were varied in addition, illiterate performance dropped considerably. Note that the tendency to confuse mirror images ('mirror invariance') may not be a perceptual limitation but an evolutionary adaptation (cf. Corballis \& Beale, 1976; Gross \& Bornstein, 1978). Kolinsky et al. (2011) argued that learning to read overcomes mirror invariance and extends to non-letter processing.

Lachmann, Khera, Srinivasan, and van Leeuwen (2012) studied whether there is a distinction in holistic processing between letters and non-letters in illiterates. Van Leeuwen and Lachmann (2004) have previously demonstrated that literates show such a differentiation in processing: letters are processed analytically, but non-letters are processed holistically. Lachmann et al. (2012) found that illiterate Indian adults, in contrast to literates from the same community, used an analytic perceptual strategy for both letters and non-letters. These authors interpreted these results as indicating that letter processing in readers "becomes habitually tied up with the analytical processing strategy. As a result, adult readers tend to no longer process simple non-letter objects analytically' (pp. 6-7). They concluded that analytic visual perception is not a secondary consequence of learning to read but that there are two primary modes of perceptual organization, namely, holistic and analytic perception.

In sum, the effects of literacy on visual perception appear rather small and are limited to situations in which cultural symbols such as line drawings and letters are presented in certain presentation modes (e.g., black and white line drawings or mirror images of alphabetic letters). Habitual letter decoding may also lead to certain visual processing strategies which impact on readers' strategies for non-letter object processing.

\section{Phonological processing}

In contrast to low level speech perception which appears to be little influenced by literacy, many studies have demonstrated important differences in illiterate's phonological processing. These differences are apparent in tasks involving phonological awareness, pseudoword repetition, phonological fluency, and phonological word-object mapping.

Phonological awareness refers to the knowledge that all words can be decomposed into smaller segments and the ability to manipulate these segments. Note that proficient reading requires awareness of the compositional nature of the units of speech because arbitrary script characters must be mapped onto the corresponding units of spoken language. Research on illiterates and children as they learn to read (see Anthony, Lonigan, Driscoll, Phillips, \& Burgess, 2003; Anthony \& Francis, 2005) suggests that phonological awareness develops from larger to 
smaller speech units. Morais, Cary, Alegria, and Bertelson (1979) investigated whether phonemic awareness arises spontaneously during development or whether it requires specific training. Thirty illiterates and thirty late literates who had taken part in adult literacy programs after the age of 15 years were asked to add or delete one phoneme (e.g., /p/) of an utterance. The result of such phoneme addition or deletion was an existing Portuguese word or a nonword (e.g., 'alcaho' resulted in 'palcaho' or 'purso' in 'urso'). The task can be done by searching memory for similar sounding words. Therefore, only non-word trials provide information about participants' segmentation abilities and phonological awareness. Morais et al. reported mean correct responses on non-word trials of $19 \%$ for illiterates but $72 \%$ for late literates. The authors pointed out that these results meant that illiterates' performance was slightly inferior to Belgian first graders (age 6 years) who were tested in the third month of the school year and that the performance of late literates was of a similar level as Belgian second graders (age 7 years) tested in the fourth month of the school year. Morais et al. concluded that phonemic awareness is not acquired spontaneously. Many studies have replicated these results (e.g., Morais, Bertelson, Cary, \& Alegria, 1986) while some also show that illiterates display better performance on tasks that require manipulation of units of larger phonological grain size such as syllable detection (Morais, Content, Cary, Mehler, \& Segui, 1989) and rhyme awareness (Morais et al., 1986; Adrian, Alegria, \& Morais, 1995). Thus, 'while sensitivity to rhyme and analysis into syllables can develop up to some point in the absence of the experience normally provided by reading instruction, analysis into phonetic segments requires that experience' (Morais et al., 1986, p. 45).

It seems however that the nature and position of the phoneme and syllable matter to how illiterates perform in phonological awareness tasks. Prakash, Rekha, Nigam, and Karanth (1993) for instance administered syllable and phoneme deletion and counting tasks to illiterates and literates speaking the Indian language Kannada. Illiterates had more difficulties with deleting syllables from the word medial position than onset and offset positions. Performance on rhyme recognition and syllable counting was not different from literates. Prakash et al. (1993) reported that the illiterates in their study did not show a position effect in tasks that required phonemic manipulation. Bertelson, de Gelder, Tfouni, and Morais (1989) reported that illiterates had fewer problems with initial vowel deletion than with initial consonant deletion when the target was a syllabic vowel. Saliency perhaps is beneficial for some spontaneous development of awareness, but clearly, further research could usefully be directed at establishing why certain sounds and positions are more challenging than others.

It is the not the ability to read and write per se but the knowledge of an alphabetic script which causes the improvement in phonemic awareness tasks. Read, Zhang, Nie, and Ding (1986) observed that phonemic awareness of Mandarin Chinese readers who had no alphabetic knowledge was similar to illiterates. Phonemic awareness of Mandarin Chinese readers who had alphabetic knowledge in contrast was similar to those of late-literates. A study by Lukatela, Carello, Shankweiler, and Liberman (1995) suggests that very basic alphabet knowledge can dramatically increase performance on phonological awareness tasks. These authors investigated phonological awareness in illiterates speaking Serbo-Croat. Some of their elderly participants had attended obligatory elementary reading instruction courses for up to a month during World War II and learned the Serbo-Croatian alphabet while others had not. None of the participants had attended formal school classes. Only the participants who had attended the reading instruction courses performed well on phonemic awareness tasks, although reading instruction had lasted at most a month and occurred more than 40 years prior to testing.

It is uncertain whether tasks which tap explicit phonological processing such as phonological awareness tasks are ecologically valid (cf. Reis \& Petersson, 2003). Phonological awareness appears not to be necessary for speech communication. Pseudoword repetition is a task that is likely to require both explicit and implicit phonological processing. Reis and Castro-Caldas 
(1997) found that illiterates performed much worse than literates in repeating pseudowords but performed as well as literates when they had to repeat real existing words (see also Kosmidis et al., 2004). Petersson et al. (2000) speculated that illiterates' difficulty in pseudoword repetition is caused by impaired processing at the level of sublexical phonological structure.

Several studies have used phonological fluency tasks. In such tasks, participants are asked to produce as many members of a pre-specified category (e.g., words which start with the sound $/ \mathrm{p} /$ ) as possible within one (or sometimes two) minute(s). The total number of words generated is most often the measure of interest. The cognitive processes underlying fluency tasks are not well understood, but it is usually assumed that the task involves clustering, i.e., generation of words within a subcategory, and switching to a new subcategory. Clustering involves phonemic analysis, whereas switching is assumed to include cognitive flexibility in shifting from one subcategory to the next (Troyer, Moscovitch, \& Winocour, 1997). As phonological fluency tasks involve phonemic analysis, it is perhaps little surprising that illiterate people perform very poorly in these tasks. Kosmidis et al. (2004) used three phonological categories: words beginning with $\mathrm{X}$ (chi), $\sum$ (sigma), and A (alpha). Participants were asked to produce as many words as possible starting with each sound. Illiterates produced on average 4.11 words, low literates 18.25 words, and high literates 32.38 words for each category.

It is evident from the studies described thus far that most research on the effect of literacy on phonological processing has used meta-phonological offline tasks. Few studies have used measures which tap behavior while a person understands spoken language. Such online methods which focus on moment-by-moment phonological processing are crucial because phonological processing happens over very short periods. Phonological effects are typically transitory and dynamic in nature, and it is important to use experimental techniques that allow the researcher to measure ongoing processing while participants' task activities can continue without being interrupted.

Huettig, Singh, and Mishra (2011) used an online eye-tracking task to examine low and high literates' use of phonological information in a situation similar to everyday contexts in which language and vision interact. Participants listened to simple spoken sentences such as Today he saw a crocodile while at the same time looking at a visual scene of four objects. Huettig and McQueen (2007) have shown previously that participants who are given a few seconds preview of the visual display retrieve phonological (i.e., the object's name; see also McQueen \& Huettig, 2014; and Huettig, Rommers, \& Meyer, 2011, for discussion of the task) and semantic information from the objects in a visual scene and use this information to direct eye gaze as the spoken words acoustically unfold. They showed that objects in the visual display overlapping in phonological and semantic information with the information accessed from the spoken word compete for visual attention. In their study, looks to phonological competitors in the visual scene (for example, looks to a crocus, both crocus and crocodile share the same word-initial phonological information) preceded looks to semantic competitors (for example, a turtle, both crocodiles and turtles are semantically related, they are both reptiles). Given the differences between illiterate and literates in offline phonological tasks (described above), Huettig, Singh et al. (2011) tested whether low literates' word-object mapping takes place (partly) at a phonological level of representation as in high literates. If so, they should look at phonological competitors more than completely unrelated distractors. If word-object mapping takes not place at a phonological level of representation, they should only look at semantic competitors. In Experiment 1, Indian high literates with 15 mean years of formal schooling and low literates with 2 mean years of formal education listened to the sentences containing a target word (e.g., 'magar', crocodile) while looking at a the visual scene. The scene contained a phonological competitor of the target word (e.g., 'matar', peas), a semantic competitor (e.g., 'kachuwa', turtle) and two completely unrelated distractor objects. In Experiment 2, the semantic competitors were replaced with another 
unrelated distractor. Low and high literates looked to the semantic competitors in Experiment 1. In both experiments, high literates shifted their eyes towards phonological competitors as soon as phonological information became available and moved their eye gaze away as soon as the acoustic information mismatched. Low literates however only used phonological information when semantic matches between spoken word and visual referent were not possible (Experiment 2), but in contrast to high literates, this phonological word-object mapping was not closely time-locked to the concurrent speech input. These findings suggest that unlike high literates, low literates do not exploit phonological matches between spoken words and visual referents for language-mediated visual orienting in an efficient manner.

Smith, Monaghan, and Huettig (2013) ${ }^{1}$ explored the hypothesis that increases in the granularity of phonological processing elicit the literacy-related changes (cf. Ziegler \& Goswami, 2005). Smith et al. (2013) ${ }^{1}$ constructed computational models with phonological representations of varying grain sizes (fine, medium, coarse; see also Smith, Monaghan, and Huettig, $2013^{2}$, for further discussion of the connectionist approach). Representational structure in the fine grained model involved distinct componential sequences of phonemes. In the moderate grained model, two components (akin to 'onset' and 'rime' representations) and in the coarse grained model only a single component (a 'word-level' representation) were encoded for each word. Smith et al. (2013) ${ }^{1}$ found that the fine grained model performed very similar to the fixation behavior of high literates: eye gaze to phonological competitors closely time-locked to the unfolding speech signal. The coarse grained model performed very similar to low literates: no time locking between speech signal, and looks to phonological competitors was observed. These simulations support the notion that literacy results in changes in the grain size of phonological mappings.

In sum, clear effects of literacy on phonological processing have been demonstrated in both online and offline tasks. Indeed, literacy has perhaps its most dramatic impact on phonological processing. Further research is required to explore the detailed mechanisms and the nature of the phonological representations involved.

\section{Semantic processing}

Most studies with illiterates and low literates on semantic processing suggest that it is much less influenced by literacy than phonological processing. Reis and Castro-Caldas (1997), for example, found that illiterates performed much better at memorizing pairs of semantically related words compared to pairs of phonologically related words. These authors argued that:

The working hypothesis that can be developed from our results is that semantics is the major attractor, or reference system, for language processing. Subsidiary or secondary systems are developed through formal learning. The written form of the words constitutes an important secondary reference system. Literate adults process words using all systems simultaneously and in parallel, whereas illiterates base most of their operations on the semantic one (p. 448).

Several studies have used semantic versions of the fluency tasks described above. The task is to produce as many members of a pre-specified category such as animals or fruits as possible within the specified time limit. Manly, Jacobs, Sano, Bell, Merchant, Small, and Stern (1999) found no difference between low literates with three mean years of formal education and illiterates on three semantic categories: animals, clothing, and food, while Reis and Castro-Caldas (1997) found a significant difference in semantic fluency between high literates and illiterates on the semantic categories animals and furniture. Kosmides et al. (2004) compared illiterates, low literates with 5 mean years of formal schooling, and high literates with 14 mean years of formal 
schooling. Three semantic categories were administered: animals, fruits, and objects. Number of years of formal schooling improved performance, the total number of words generated for the three categories were 31 for the illiterates, 40 for the low literates, and 50 for the high literates. Kosmides et al. suggested, we believe rightly, that this improvement is most likely due to general factors associated with schooling such as increased vocabulary, more efficient memory strategies, and perhaps also appreciation of the importance of examinations on artificial tasks. A study by Da Silva, Petersson, Faisca, Ingvar, and Reis (2004) is particular illuminating. They compared illiterates and literates on a semantic category which is more ecologically valid for illiterate people, namely, edible things that can be bought at a supermarket and a semantic control category (animals). There were no differences between groups on the supermarket category, but literates performed better than illiterates on the animal category task. The Da Silva et al. study therefore implies that differences in semantic fluency between literates and illiterates depend on the semantic category examined. Crucially, it also demonstrates that researchers must be careful not to jump to quick conclusions about illiterates' and low literates' cognitive abilities based on evidence from tasks which are of little relevance to illiterates in their daily lives.

The question arises whether differences in semantic tasks simply reflect differences in experience (e.g., a smaller amount of vocabulary knowledge) or whether they reflect more substantial differences in general processing speed or cognitive efficiency. General processing speed has previously been suggested as being the cause of ageing-related differences in a great variety of cognitive tasks (e.g., Kail \& Salthouse, 1994; Salthouse, 1996). Interestingly, processing speed has been linked to the speed with which neural signals are conducted along axons. The speed of neural transmission moreover is related to the degree of myelination (Gutiérrez, Boison, Heinemann, \& Stoffel, 1995), and it has been shown that learning increases myelination (cf. Bengtsson, Nagy, Skare, Forsman, Forssberg, \& Ullén, 2005). This is a potential mechanism by which learning to read may enhance processing speed. As mentioned above, Huettig et al. (2011) found that semantic word-object mapping occurs with a similar time-course in both low and high literates. Huettig et al. (2011) suggested that for illiterates and low literates, there is a bias for word-object mapping at the semantic level and that mapping at the phonological level in this population only takes place when pushed by restrictions in the representational content of the environment (e.g., if semantic matches between spoken words and visual objects are not present). Note though that the magnitude of the semantic effects was nevertheless significantly reduced in the low literate group, suggesting possible differences between groups in semantic processing. Smith et al. (2013) ${ }^{1}$ explored the hypothesis that differences in general processing speed may partly underlie the difference in the semantic effects between low and high literates. They simulated general processing speed in a computational model of language-mediated eye gaze and provided some evidence that low processing speed can lead to small but significant decreases in the magnitude of semantic wordobject mapping. Further work is needed to explore whether differences in processing speed and/or cognitive efficiency are characteristic of (il)literate processing.

\section{Visual attention}

Literacy has been found to have substantial effects on anticipation of visual objects referred to by spoken language and on the way we sample the visual world when we are looking for targets among competing stimuli.

\section{I. ANTICIPATORY EYE MOVEMENTS}

Mishra, Singh, Pandey, and Huettig (2012) explored whether predictive language processing is influenced by literacy. More precisely, they investigated whether high proficiency in reading is 
related to anticipatory language-mediated visual orienting. This is an interesting question because it has been proposed that prediction is a fundamental principle of human cognition (James, 1890; Pezzulo, Hoffmann, \& Falcone, 2007). In line with this view, research using event-related potentials (ERPs) suggests that language users can use linguistic input to preactivate representations of upcoming words before they are encountered (DeLong, Urbach, \& Kutas, 2005; Federmeier \& Kutas, 1999; Van Berkum, Brown, Zwitserlood, Kooijman, \& Hagoort, 2005; Wicha, Moreno, \& Kutas, 2004). Similarly, eye-tracking studies have shown that listeners can use semantic (e.g., Altmann \& Kamide, 1999, Mani \& Huettig, 2012), syntactic (e.g., Kamide, Scheepers, \& Altmann, 2003), and visual form (Rommers, Meyer, Praamstra, \& Huettig, 2013) information to anticipate what object a speaker will refer to next in the listener's visual environment. Most of these studies however have been conducted with (highly literate) students. The question arises whether low proficiency language users anticipate up-coming language input as much as high proficiency language users. It is important to note in this regard that low and high literates comprehend and produce speech every day. This experience should bring predictive abilities during normal 'every day' spoken language processing to a ceiling level. Thus, if prediction is fundamental to spoken language processing, then it should not be modulated substantially by literacy levels.

Mishra et al. (2012) presented Indian low and high literates with simple every day spoken sentences containing a target word (e.g., 'door'). While participants listened to the sentences they looked at a visual display of four objects (a target, i.e., the door and three distractors). The spoken sentences were constructed to encourage anticipatory eye movements to the visual target objects. The high literacy group started to shift their eye gaze to the target object well before target word onset. The low literates did not anticipate the targets and looked at the target objects more than a second later that is well after the onset of the target. These findings suggest that literacy modulates predictive spoken language processing. High reading proficiency appears to be important even for prediction in basic every day spoken language processing. These data are compatible with the notion that prediction is perhaps an important aspect but not a crucial principle of language processing. Further research is required to investigate the mechanisms by which literacy affects anticipation. Is literacy simply a proxy for language experience? Or does actual reading proficiency fine-tune anticipatory mechanisms in specific ways? Reading and spoken language comprehension, for example, differs in the amount (approx. 250 vs. 150 words/min) of information that is processed per time unit. In order to maintain such a high reading speed, prediction is presumably helpful. High literates may be able to exploit these abilities for other cognitive activities such as language-mediated visual orienting.

\subsection{VISUAL TASKS AND DIRECTIONAL BIASES}

Matute, Leal, Zarabozo, Robles, and Cedillo (2000) administered a stick copying task to Mexican illiterates, low literates with less than 4 years of formal schooling, and high literates with up to 12 years of formal schooling. Four types of stick constructions of increasing complexity were presented. Participants were asked to copy the sticks by arranging small wooden sticks on a piece of paper. Low literates were found to perform well. Overall, only disarticulation errors were significantly more frequent in the illiterate group. The disarticulation errors were sticks overlapping with each other, sticks which were too far apart from each other, and displaced vertices. Matute et al. concluded that 'appropriate disarticulation is a crucial requirement for the writing of a whole text, implying separation of words' (p. 672).

In the broader human population, there is a general left hemifield (i.e., right hemisphere) bias in tasks requiring fine discrimination of visual stimuli (Kimura, 1966; Jewell \& McCourt, 2000; Nicholls \& Roberts, 2002; Landau \& Fries, 2012). Several studies with illiterate and literate 
participants have shown that there is an additional direction bias due to the direction of the writing system (e.g., left-to-right or right-to-left).

Padakannaya, Devi, Zaveria, Chengappa, and Vaid (2002) found that illiterate Urdu speaking adults did not show any right-left bias in two tasks: naming linearly arranged pictures and recalling of linearly arranged pictures after brief exposure. Urdu-speaking literate adults and Arabic-speaking literate adults however did show such a right-to-left scanning bias. Both Urdu and Arabic are right-to-left writing systems. Padakannaya et al. concluded that directional scanning habits are related to reading habits. Vaid, Singh, Sakhuja, and Gupta (2002) asked participants to draw a quick sketch of simple objects (e.g., a pencil, a fish, and a house). The predominant stroke direction of the participants was noted. Vaid et al. observed that script directionality and handedness affected preference for drawings in literates. Illiterates showed no overall bias. Right-handed illiterates showed a left-to-right stroke bias, whereas left-handed illiterates showed a right-to-left stroke bias. Both right and left-handed Urdu literates however showed a right-to-left stroke bias. Vaid et al. concluded that hand movement-related directional biases and directional scanning biases arise at least partly from reading and writing experiences (see also Chatterjee, 2001; Dobel, Diesendruck, \& Bőlte, 2007; Eviatar, 1995, 1997, 2000; Maas $\&$ Russo, 2003; for research on the effect of script direction with literate adults and children).

\subsection{VISUAL SEARCH}

Brucki and Nitrini (2008) compared illiterate with low literate river bank dwellers of the Amazon region of Brazil on a cancellation task. Participants were shown random arrays of geometric visual stimuli. The task was to mark every open circle with a single slanted line as fast as possible. Illiterates (94\%) were significantly more likely than the low literates $(80 \%)$ to conduct a random search for targets. Bramao, Mendonca, Faisca, Ingvar, and Petersson, and Reis (2007) required illiterate and literate participants to touch visual targets such as a red square among yellow squares which appeared on a computer screen as quickly as possible. Illiterates were overall less accurate and slower compared to literates in target detection. More interestingly, literates were faster in detecting targets on the left side of the screen. Illiterates' performance did not reveal such a directional bias.

The results of Bramao et al. (2007) are indicative with regard to literacy-related differences in selective attention, but they leave some questions open. It is unclear from these studies whether the differences are due to less experience with abstract geometric stimuli. Moreover, it is uncertain whether these effects reflect attentional processes or processes at stages after target selection has taken place (i.e., decision processes or response selection). Olivers, Huettig, Singh, and Mishra (2014) compared low to high literacy observers in two experiments on an easy (color search: finding a red chicken among green chickens) and a more difficult (shape search: finding a skinny chicken among fat chickens) visual search task. In order to put low literates not at an immediate disadvantage, the tasks involved looking for different types of chicken. Low literates were slower in both experiments. Detailed reaction time analyses and eye movement analyses revealed that the slowing was partly due to differences in parallel (that is display wide) sensory processing. The main driver of differences between groups however was post-selection processes. Low literates needed more time between target fixation and generation of the manual response. High and low literates also differed in the way search performance was distributed across the visual display. High literates showed a shift in the distribution of covert visual attention to central and right parts of the visual field. High literacy however was also associated with a more general bias towards the top and the left (especially in the more difficult search) compatible with reading direction of the Hindi-speaking participants. Olivers et al. concluded that learning 
to read results in an extension of the functional visual field from the fovea to parafoveal areas and some asymmetry in scan pattern influenced by the reading direction.

To conclude, literacy has important cognitive consequences for visual attention which go beyond the processing of orthographic stimuli. Learning to reading changes the spatial distribution of visual search even for non-linguistic materials and extends the function field of view into parafoveal areas.

\section{Memory}

It is conceivable that (at least some) individuals in oral societies have (or had) superior memory abilities because of the rote learning of elaborate songs in many traditional oral societies. For example, the Vedic chants of India, some with tens of thousands of verses, have been passed on for as long as 3000 years. In order to ensure that the chants are passed on accurately certain mnemonic techniques are used. One such technique involves the recitation of every two adjacent words first in their original order, then in the reverse order, and finally again in the original order before moving on to the next word.

The old Greeks were the first society in history in which large parts of the population could read and write. They were also the first to speculate how writing would affect the memory of literate people. Socrates thought that knowledge of reading and writing would have adverse effects on memory. He feared that literates would become forgetful because they could always rely on external memory aids (see Scribner \& Cole, 1981, for further discussion). Vygotsky (1978) argued that there are two types of memory: 'natural memory' (based on the direct retention of mainly perceptual experiences) and 'indirect mediated memory' (based on 'a new culturally-elaborated organization', p. 39). Vygotsky believed that illiterates relied mainly on natural memory. Many others have speculated on the link between literacy and memory; however, until recently, there has not been any rigorous experimental testing of the memory abilities of illiterate individuals.

Scribner and Cole (1981) administered two recall tasks to illiterates, Vai script literates, Arabic script literates, Vai and Arabic script biliterates, and schooled literates. In the first recall task, participants were first presented with 24 common objects and then later asked to recall them. In the second recall task, the experimenter read out the 24 names of the objects, and participants were asked to recall them in any order they wanted. Biliterates and schooled literates recalled more items in the second task, but there was no overall effect of literacy in both tasks. Scribner and Cole (1981) were especially surprised that their Arabic script monoliterates did not show any evidence for preservation of serial order in the recalled items despite years of practice in memorizing the Qur'an. In some later refined recall tasks Scribner and Cole (1981) did detect significantly better recall performance for Arabic script monoliterates compared to Vai script monoliterates which suggests that years of Qur'anic rote learning has some beneficial effects on general recall performance. The effects however were surprisingly small. Scribner and Cole (1981) also investigated the recall of folk stories with 80 participants (illiterate adults, Vai script monoliterate adults, Arabic script monoliterate adults, unschooled children, and educated adults with between 4 and 12 years of schooling). There was no difference in recall between the adult groups which led Scribner and Cole to conclude that memory for oral stories is not affected by literacy.

More recent experimental studies comparing memory abilities of illiterates and literates have found much poorer memory performance of illiterates in standardized memory tasks. Although illiterates show good memory abilities in immediate sentence recall (Ardila, Rosselli, \& Rosas, 1989), they perform poorly on digit span tasks (Ardila et al., 1989; Reis, Guerreiro, Garcia, \& Castro-Caldas, 1995; Reis et al, 2003). In the digit span task, participants are typically required 
to repeat forward, or sometimes backward, a number of digits. Reis et al. (2003) showed that number of years of formal schooling improved performance. The mean digit spans in their study were illiterates 4.1, low literates with 4 years of schooling 5.2, and high literates with 9 years of education: 7.0. These results suggest that there is a graded effect of formal schooling on performance on digit span tasks and perhaps on standardized short-term memory tests more generally. Interestingly, Petersson, Ingvar, and Reis (2009) found no significant difference between illiterates and low literates on the Wechsler spatial span task but replicated the significant difference on the Wechsler digit span. Petersson et al. argued that this 'represents a first hint that verbal short-term memory might be influenced by literacy and formal education, and this is possibly related to more effective verbal working memory representations in literate individuals (e.g., chunking)'.

To conclude, there is little concrete evidence that lack of written external memory aids and a custom of rote learning of traditional songs and stories in illiterates leads to better memory abilities. Contrary, research using standard short-term memory tasks has found that literacy results in better performance in these tasks. Standard memory tasks such as digit span however almost certainly lack some ecological validity with individuals who never received any formal education. There is also a need for future research to assess illiterates on tasks that measure other forms of memory such as long-term, procedural, and episodic memory.

\section{Generalization, abstraction, deduction, and inference}

A large part of Luria's work on illiterates in Uzbekistan and Kirghizia concerned the capacities for generalization, abstraction, and inference. Luria was a follower of the Marxist/Communist doctrine that cognition is a product of human activity rather than the cause. Luria and Vygotsky, in line with Marxist-Leninist ideas, thought that the elimination of illiteracy in the Soviet Union would lead directly to a revolution in cognitive activity. Like Lévi-Bruhl, they assumed that fundamental changes in societies' social conditions lead to fundamental changes in cognitive processes. Luria (1976) argued that:

Higher cognitive activities remain socio-historical in nature, and that the structure of mental activity not just the specific content but also the general forms basic to all cognitive processes - change in the course of historical development (p. 8).

Uzbekistan in the early 1930s provided Luria with the perfect opportunity to explore these ideas. An extensive network of schools had opened up with the communist revolution and regions which had been one hundred percent illiterate until then became exposed to large scale literacy programs. Due to the large socioeconomic and cultural changes brought about by the revolution, Uzbekistan in the early 1930s was a country in transition from mostly cattle-raising families to collective Soviet agricultural methods. This allowed Luria to compare completely illiterate villagers with semi-literate people already involved in modern Soviet society. Luria put great effort in making his participants comfortable with testing procedures. He did not use standardized psychometric tests but developed his own which he thought to be more meaningful to his participants than the tests developed and validated in other cultures.

Luria found that illiterates did not name geometrical figures with their categorical names (e.g., circle or triangle). Squares were labeled 'window frames', triangles 'mountains', circles 'plate' or 'coin', and straight lines 'road' or 'thread'. He observed that his illiterate participants had a very strong tendency to group objects suitable for a specific purpose. They strongly resisted grouping objects according to taxonomic categories divorced from situational context and found this a very strange procedure. For instance, when shown pictures of a glass, a sauce 
pan, spectacles, and a bottle, one participant said: 'these three go together, but why you've put the spectacles here, I don't know. Then again, they also fit in, if a person doesn't see too good, he has to put them on to eat dinner'. Another participant stated: 'I don't know which of these things doesn't fit here. Maybe it's the bottle? You can drink tea out of the glass --that's useful. The spectacles are also useful. But there's vodka in the bottle - that's bad'. When asked 'could you say the spectacles don't belong in this group?' he responded 'no, spectacles are also a useful thing'. The participant was then provided with a full explanation that three of the objects belonged to the category 'vessels'. Then, the experimenter asked 'so wouldn't it be right to say the spectacles don't fit in this group?' but the participant insisted that 'the bottle doesn't belong here. It's harmful... if you're cooking something on the fire, you've got to see what you're doing, and if a person's eyes are bothering him, he's got to wear a pair of glasses'. The experimenter then responded 'but you can't call spectacles a vessel, can you?' but the participant continued to insist that 'if you're cooking something on the fire, you've got to use eye glasses or you just won't be able to cook'. (pp. 57-58). Participants with 1 or 2 years of schooling however found it easy to shift from situational to abstract categorization which suggests that only little training is required to grasp efficient categorical classification.

Luria concluded that simply lack of experience underlies the differences in categorization abilities:

When the pattern of their lives changes and the range of their experience broadens, when they learn to read and write, to become part of a more advanced culture, the greater complexity of their activity stimulates new ideas. These changes, in turn, bring about a radical reorganization of their habits and thinking, so that they learn to use and appreciate the value of theoretical procedures that formerly seemed irrelevant (p. 79).

Luria also administered syllogisms (i.e., a logical argument in which one proposition is inferred from others), for example, 'cotton grows well where it is hot and dry. England is cold and damp. Can cotton grow there or not?' Luria found that participants refused to make inferences which went beyond their personal experience. Typical responses were the following:

I don't know if there's cotton or not.It's chilly here too.I don't know... if it's cold, it won't grow, while if it's hot, it will. From your words, I would have to say that cotton shouldn't grow there. But I would have to know what spring is like there, what kinds of nights they have (pp. 109-110).

These responses again most likely reflect a lack of experience with syllogisms rather than any substantial deficits in deduction and inference. Luria concluded that:

For the non-literate subjects, the process of reasoning and deduction associated with immediate practical experience follow well-known rules. These subjects can make excellent judgments about facts of direct concern to them and can draw all the implied conclusions, displaying no deviation from the 'rules' and revealing much worldly intelligence. The picture changes, however, just as soon as they have to change to a system of theoretical thinking (p. 114).

Moreover, Scribner and Cole (1981) showed that illiterates do better at meaningful syllogisms. They argued that syllogisms reflect a metalinguistic skill and that poor performance in the task does not show an inability to reason logically but rather a poor understanding of that particular verbal form. Scribner and Cole (1981) showed that discourse context affected how illiterates understood the task. Illiterates performed poorly on problems such as:

All houses in Liberia are made of iron.My friend has a house in Liberia.Is my friend's house made of iron? 
Many illiterates for instance rejected the first premise because they knew it to be false. The illiterate participants however performed much better when presented with problems about which they had no fixed beliefs or personal knowledge:

All stones on the moon are blue.The man who went to the moon saw a stone.Was the stone he saw blue?

Scribner and Cole (1981) therefore argued that 'these studies of logical-verbal problem solving cast doubt on hypotheses that implicate literacy directly in the acquisition of metalinguistic knowledge about the properties of propositions' (p. 156).

Scribner's and Cole's conclusions however have been challenged. Goody (1987) has criticized this work by arguing that one cannot only look at the individual. He argued that literacy is a historical process, and thus, one must look at the consequences of literacy on society as a whole. Similarly, Olson (1994) has argued that 'we cannot grasp the full implications of literacy by means of research which simply compare readers with non-readers. We require a richer more diversified notion of literacy' (p. 43). Although we have some sympathy with these views, we believe that these issues should not stop us from asking (and answering) precise questions. We may ask questions about the impact of literacy on society at large, but there is no good alternative to comparing readers with non-readers. Any theoretical claim is only as strong as the experimental evidence available to support it.

\section{Reasoning and problem-solving}

Many 20th century scholars were very pessimistic about the reasoning abilities of individuals in pre-literate societies. Lévi-Bruhl (1923), for instance, characterized illiterates' cognitive processing as a pre-logical mode of thinking. He argued that illiterate societies are particularly prone to magical beliefs which, he proposed, were a result of their inability to distinguish sign from cause. It is interesting that Lévi-Bruhl managed to completely ignore the high levels of paranormal belief in literate societies. For example, a Gallup poll (May 2001) found that 50\% of Americans believe in ESP (extrasensory perception), $42 \%$ in that houses can be haunted, $41 \%$ in that people on earth are sometimes possessed by the devil, and $26 \%$ in witches. Given this there seems nothing particular to pre-literate societies with regard to magical and paranormal belief.

Luria (1976) argued that:

The significance of schooling lies not just in the acquisition of new knowledge, but in the creation of new motives and formal modes of discursive verbal and logical thinking divorced from immediate practical experience (p. 133).

In other words, the illiterates' difficulty lies in performing formal logical operations which are divorced from or even contradict their own experience. Luria, for instance, gave illiterates the following problem:

'It is twenty kilometers from here to Uch-Kugan, while Shakhimardan is four times closer [in actual the reverse is true.] How many kilometers is it to Shakhimardan'. A typical participant said 'What! Shakhimardan four times closer?! But it's farther away' to which the experimenter responded 'yes, we know. But I gave out this problem as an exercise.' The participant struggled to make sense and responded: 'I've never studied, so I can't solve a problem like that! I don't understand it! Divide by four? No...I can't.' The problem was then repeated and the participant calculated and arrived at the correct solution stating: 'if you divide by four, it'll be...five kilometers... if you divide twenty by four, you have five! Then Shakhimardan will be closer.' (p. 127). 
Thus, it is not the case that illiterates have great deficits in reasoning and problemsolving per se; it is just that they lack the experience to apply these abilities to problems which are abstracted away from daily experience. Effects of literacy on reasoning and problem solving seem more linked to formal education than reading acquisition per se. We will return to this issue in the conclusions.

\section{Literacy and the brain}

The great advances in imaging technology and the ascent of cognitive neuroscience over the last 30 years have not bypassed the study of the illiterate mind. A small number of studies conducted over the past 10-15 years have used neuroscience methods to investigate the effect of literacy on the adult brain. Electrophysiological and structural and functional imaging methods have been applied.

\section{I2.I. ELECTROPHYSIOLOGICAL STUDIES}

As far as we know, Ostrosky-Solís, García, and Perez (2004) are the only researchers who have used event-related potentials (ERPs) with illiterate participants. As the recording of ERPs is likely to become more important in future for the study of literacy-related cognitive processing, we provide a brief description of the method and the Ostrosky-Sol\#x1EC9; et al. study here. ERP studies measure electrical signals (EEG) through electrodes attached to the skull. A large numbers of neurons aligned in parallel orientation must fire in synchrony for this signal to be detectable. The electrical signals from the electrodes placed on the skull are compared to a reference site, for instance, the mastoid bone behind the ear which is assumed to be relatively uninfluenced by the experimental manipulation, while participants are engaged in an experimental task. An advantage of ERPs is that they have an excellent temporal resolution. The method however has poor spatial resolution and is thus well suited for studying the timing of cognitive processes but much less appropriate for localising neural activity.

In their study, Ostrosky-Solís and colleagues presented auditory probe stimuli to Mexican illiterates and high literates with more than 12 years of formal education. Amplitudes of probe ERPs were recorded during a control and an experimental condition. In the experimental condition, participants were asked to memorise a list of 30 abstract high frequency nouns such as liberty, happiness, and peace. These words were presented at a rate of half a word per second. Amplitudes during the control condition (when participants heard a probe $500 \mathrm{~Hz}$ click stimulus) did not differ between groups, and ERP amplitudes during the memory task showed left hemisphere attenuation in both groups. However, illiterate participants, in contrast to the high literates, did not show any significant attenuation in parieto-temporal areas in the memory task. Parieto-temporal areas have been associated with word and object processing (e.g., Vandenberghe, Price, Wise, Josephs, \& Frackowiak, 1996). Ostrosky-Solís et al. thus argued that these results show that 'learning how to read and write demand an intrahemispheric specialization with an important activation of parieto-temporal areas' (p. 33). However, as discussed above, ERPs are not well suited to localise brain activity. There is currently a lack of ERP research directed at the timing of cognitive processing in illiterates for which electrophysiological methods are more appropriate. Methods which are better suited to localize brain structures and activity are neuroimaging techniques to which we turn next.

\section{I2.2. STRUCTURAL IMAGING}

Structural imaging methods can reveal differences in brain structure such as the concentration and architecture of white and grey matter. Important approaches are voxel-based morphometry 
(VBM) and diffusion tensor imaging (DTI). VBM for instance can be used to estimate whether learning to read and write leads to an increase in the density of grey matter in particular brain regions. DTI is a useful method to investigate the connectivity of white matter between different brain regions and can be used to examine whether reading changes the connectivity of certain white matter fibers.

Castro-Caldas, Cavaleiro Miranda, Carmo, Reis, Leote, Ribeiro, and Ducla-Soares, (1999) first reported differences in the structure of the corpus callosum between illiterates and literates. White matter tracts connect different cortical regions within the same and the two different hemispheres (commissures). The corpus callosum is the most important commissure. CastroCaldas and colleagues found the posterior mid-body region of the corpus callosum to be significantly thinner in Portuguese illiterates than in Portuguese literates. The authors speculated that this difference may be due to differences in interhemispheric interactions in literates and illiterates. Similarly, Petersson, Silva, Castro-Caldas, Ingvar, and Reis (2007) using VBM found greater white matter intensity in the posterior third of the mid-body region of the corpus callosum of literates than in low literates with 4 years of schooling. Carreiras and colleagues (2009) found a greater amount of white matter in the splenium of the corpus callosum of individuals who acquired reading late compared to illiterates despite both groups being matched for performance on the Raven non-verbal IQ-test and other control tests. VBM analyses in the late literate group revealed that grey matter increases in areas associated with higher level visual processing, areas associated with phonological processing, and in regions associated with semantic processing. Carreiras and colleagues concluded that learning to read strengthens connections between left and right angular gyri which are mediated by white matter pathways trough the splenium of the corpus callosum.

\section{I2.3. FUNCTIONAL IMAGING}

Two important measures of brain activity with high spatial resolution, associated with cognitive processing are positron emission tomography (PET) and functional magnetic resonance imaging (fMRI). PET is a measure of changes in blood flow to a brain region using radioactive traces injected into the bloodstream. These changes in blood flow during an experimental condition are compared to the blood flow in a baseline condition. $\mathrm{AMRI}$ is a measure of the BOLD signal, i.e., the concentration of deoxyhemoglobin in the blood. Increases in neural processing lead to changes in the BOLD signal over time. As for PET studies, most AMRI studies compare the response (i.e., the BOLD signal) during a task of interest with the BOLD response in a similar baseline task.

Castro-Caldas, Petersson, Reis, Stone-Elander, and Ingvar (1998) asked six literates and six illiterates to repeat auditorily presented words and pseudowords during PET scanning. The illiterate participants repeated pseudowords correctly on only 33\% of trials (literates $84 \%$ of trials), but word repetition accuracy scores for literates $(98 \%$ correct) and illiterates $(92 \%$ correct) were similar. These differences were reflected in the imaging data. There were no differences in brain activation during word repetition, but during pseudoword repetition, literates showed activation in regions such as the left anterior cingulate, right frontal operculum/anterior insula, left lentiform nucleus, and anterior thalamus which were not activated in the illiterates. PET scans of the illiterate group however showed activation in an area not activated in the literates: the right middle frontal-frontopolar region. The authors took this result to argue that because of the absence of an adequately configured neural network, illiterates recruit general purpose systems to support pseudoword repetition.

Petersson and colleagues (2000), similarly, found no differences in PET activation between literates and illiterates using the word repetition task but significant differences between word 
and pseudoword repetition in the illiterate group. Petersson and Reis (2006) have argued that 'differences in the phonological loop interactions might represent a primary difference between the two literacy groups'. Petersson et al. (2007) used PET with illiterates and low literates with an average of 4 years of schooling. Participants were presented with spoken words and asked to listen silently and to memorize the words. Literates showed greater activity in a number of regions such as the left inferior parietal and parieto-temporal region, the left frontopolar region, the left inferior temporal lobes, the precuneus, and the right mediolateral cerebellum. Illiterates in contrast showed greater activity in the anterior cingulate cortex, the frontal operculum and anterior insula bilaterally, and in the right inferior parietal and parieto-temporal regions. Further analysis revealed a positive functional left-right difference in the literate participants. The illiterates on the other hand showed a negative left-right difference in the inferior parietal region. Petersson and colleagues concluded that literates are relatively left-lateralized and that 'literacy influences the functional balance between the left and right inferior parietal regions' (p. 797).

Dehaene and Cohen (2007) pointed out that reading as a recent cultural invention must be under strong evolutionary anatomical and connectional constraints. They argued that reading therefore must make use of neural networks which are 'sufficiently close to the required function and sufficiently plastic as to reorient a significant fraction of their neural resources to this novel use' (p. 384). Cohen, Dehaene, Naccache, Lehéricy, Dehaene-Lambertz, Hénaff, and Michel (2000) suggested that an area in the left occipito-temporal sulcus is unique to written word processing: an area which has come to be named visual word form area (VWFA). VWFA activation during reading appears to occur irrespective of the writing system (Bolger, Perfetti, \& Schneider, 2005). Importantly, Dehaene and Cohen (2007) proposed that the VWFA becomes functionally specialised during reading.

Dehaene et al. (2010) conducted a fMRI study with 10 illiterates, 22 ex-illiterates, and 31 literates from Brazil and Portugal. Tasks presented to participants included horizontal and vertical checkerboards, written and spoken sentences, motor commands, calculation problems, faces, houses, tools, letter strings, falsefonts, moving checkerboards, and four auditory lexical decision tasks. Reading sentences in literates resulted in enhanced activation of the right occipital cortex, the VWFA in the left ventral visual cortex, the left perisylvian temporal, and frontal language areas. The authors considered the results to be strong evidence that literacy results in the emergence of the VWFA as a cortical site that becomes increasingly more responsive, in strength and specificity, to written stimuli than other visual stimuli. In addition, the data suggested that, at the VWFA, learning to read competes with the cortical representation of faces. Dehaene et al. proposed that orthographic representations expand in the ventral visual system and interfere with the expansion of faces and houses into the surrounding cortex. Literacy was also found to result in increased occipital responses to black and white stimuli. Reading performance predicted responses to horizontal but not vertical checkerboards. The authors concluded that 'literacy results in a form of perceptual learning that refines the earliest stage of cortical visual processing' (p. 4). There was also much increased activation to spoken sentences in literates in the planum temporale. Dehaene et al. interpreted this finding as indicating that this region is implicated in the enhanced phonemic processing which typically accompanies literacy. Differential responses to spoken sentences in literates and illiterates also suggested that there can be top-down activation of the VWFA during speech processing. Dehaene and colleagues proposed thus that both, online activation of an orthographic code (i.e., activation of the Planum temporale) and additional and optional orthographic recruitment (i.e., activation of the VWFA), are involved when spoken words are processed in literates. Finally, the data suggested that VWFA activation to written words increases sharply from illiterates to exilliterates, but then reaches a plateau, and does not appear to increase much further with increased reading proficiency. 
There is no doubt that the results from these structural and functional imaging studies are intriguing. On the other hand, we believe it is fair to say that some caution is warranted. First, most of the studies above were conducted with very low participant numbers (e.g., 10 illiterates in the Dehaene et al. study). Second, there has been notable variation in the demographic characteristics of the participants and in the participating laboratories even within single studies. The participants in Dehaene et al., for example, were tested either in Brazil, Portugal, or France. Neuroimaging took place in Brazil or France. The ten illiterates in the Dehaene et al. study consisted of five illiterates from rural areas and five illiterates from urban centres. Their average age was 53 years. Some of the illiterates reported to have attended adult alphabetization classes (though apparently with little success). The ten illiterates were all from Brazil but compared to Portuguese ex-illiterates and literates as well as Brazilian ex-illiterates and literates. Replications are of course always useful but given these participant numbers and characteristics, we believe, even more so (ideally with young adults from similar socio-economic backgrounds). Third, some concerns about the interpretation of fMRI data remain (cf. Coltheart, 2006; Page, 2006; Uttal, 2001; Vul, Harris, Winkielman, \& Pashler, 2009). There is for example some controversy about the nature of the VWFA. Dehaene and Cohen (2007) are careful to state that the label VWFA 'should not be taken to imply that this cortical sector is entirely dedicated to reading, but solely that it comprises reproducible and specific neural mechanisms for recognizing written characters' (p. 386); their suggestions about the VWFA however have not been without criticism. Price and Devlin (2003) have pointed out that reading involves activation of a distributed set of regions and that activation in the VWFA is not specific to visual word forms. Price and Devlin conclude that it is therefore misleading to label this region 'visual word form area'. Wright, Mechelli, Noppeney, Veltman, Rombouts, Glensman, Haynes, and Price (2008) compared VWFA activation of written words to pictures of objects. According to the authors some differential activation was found but these effects '(i) do not withstand statistical rigour; (ii) do not replicate within or between subjects; and (iii) are observed in voxels that also respond to pictures of objects' (p. 986). Moreover, Nestor, Behrmann, and Plaut (2013) recently presented evidence that orthographic processing and face processing rely on common ventral cortical networks. This, they argue, speaks against a dedicated circuit for orthographic processing.

\section{Can literacy be detrimental?}

Are there any detrimental effects of literacy, or in other words, do illiterates excel in certain cognitive tasks? In countries with low literacy rates, the belief that illiterate people are better than literates in recognizing facial emotions is widely held. Moreover, as mentioned above, Dehaene and colleagues (2010) have suggested that face perception abilities will suffer as individuals become literate because orthographic representations 'invade' the ventral visual system and interfere with the enlargement of faces and houses into the surrounding cortex.

There is no solid experimental evidence from behavioral studies to support such claims. Huettig et al. (in preparation) compared complete illiterates and literates from the same village and the same community of Indian society on the recognition of the emotions of the standardized Ekman (Ekman \& Friesen, 1975) faces. There was no hint of a difference between the two groups. The Ekman faces are sometimes criticized for being culture-specific (i.e., Western), and thus, perhaps these results have to be interpreted with some caution. Orihuela, Carreiras, and Dunabeita (2013) have also investigated whether illiterates and literates differ in face perception. These authors found in fact the opposite effect, illiterates made more errors than literates in a face recognition task of varying degrees of difficulty. Thus, as in the case of memory research, literacy may improve face perception rather than being detrimental. Note also that the 
Lachmann et al. (2012) findings do not mean that readers have lost the ability to process letters holistically. van Leeuwen and Lachmann (2004) have shown that contrasting strategies of holistic processing in shapes and analytic processing for letters resulted in uniformly holistic processing if task demands required it. This shows that literates do not lose the ability to perform holistic letter processing but that they strategically refrain from it. Findings such as these make us skeptical that superior performance of illiterates over literates in any cognitive or perceptual task is likely to be demonstrated in future.

\section{Conclusions}

In this review, we critically examined the current-state-of-the-art of research into the influence of literacy skills on cognitive processing. The reviewed literature makes clear that many aspects of perception and cognition have been explored with regard to their relation to literacy. Some substantial progress has been made, yet it is also apparent that the study of the effect of reading, writing, and formal schooling on (adult) cognition is still in its infancy. The reasons for this state of affairs are mostly historical. Since the advent of the cognitive revolution in the 1950s most of research in psychology and related areas has been carried out in a small number of Western countries with no or few illiterate individuals. The majority of studies thus have relied on (mostly female) older adults from very specific geographical and socioeconomic backgrounds (i.e., poor agricultural areas in Portugal or Greece and a few Latin American countries) though often an attempt to use age-, socioeconomic background-, and gender-matched control groups was made. Western illiterates are arguably very atypical illiterate samples. They tend to be fewer in number and differ in age, cultural factors, and reasons for illiteracy, from the vast majority of the world's one billion illiterates who almost all reside in developing countries. Indeed, it has been argued that the Western (mostly student) participants used in most experiments in experimental psychology and cognitive neuroscience are the WEIRDest (Western Educated Industrialized Rich Democratic) people in the world from which to draw general conclusions about human behavior (Henrich, Heine, \& Norenzayan, 2010; see also Arnett, 2008). We believe that it is unclear (or at least an open empirical question) how much one can generalise from the experimental results obtained with these samples to the hundreds of millions of young illiterate adults in the developing world. We conjecture that research with young illiterate or low literate adults in developing countries will be the most informative. Experimental and control groups recruited from the same geographical and societal communities will be crucial.

Note in this regard that the unique window to explore effects of literacy on cognition with young adults in developing countries may be limited to the next few decades. Fortunately, many countries have increased their efforts to eradicate illiteracy. According to the official statistics illiteracy in China is being eradicated swiftly with more than $90 \%$ of Chinese now being literate. If the literacy rate in India continues to rise at the same pace as in the last decades, then illiteracy in India will become a thing of the past within the next 30 years. Even if this should turn out to be overly optimistic, the message should be clear, we do have the possibility to study healthy illiterate adult minds who are socially well integrated in their societies, but we need to grasp the opportunity now.

The review of the literature suggests that literacy may have its most specific influences on phonological processing and visual attention. In other words, learning to read and write influences some processes and abilities much more than others. We believe it is useful to make a distinction between proximate and distal effects of literacy. The research evaluated in this review suggests that literacy has some proximate effects, for example: an increased phonological awareness, a much improved ability to repeat phonological structures (as in pseudoword repetition) and to efficiently use phonological information to map spoken words onto visual 
objects in the environment, asymmetries in scanning patterns of visual scenes, and an extension of the functional field of view from foveal to parafoveal areas. Other effects of literacy are likely to be more distal, for example: number of words produced in semantic fluency tasks, digit span in memory tasks, performance with syllogisms, and reasoning about abstract problems. We propose that proximate effects are more likely due to the acquisition of reading, whereas distal effects are more likely due to participation in formal education. There is however no neat distinction between the two. Distal effects fit best with the notion of literacy as a proxy for experience.

It is apparent that most studies have been conducted using meta-linguistic offline tasks. More recently, methods with good temporal and spatial resolution, that is online methods and neuroimaging methods, have been applied. This is an important development as much of cognition unfolds very rapidly and dynamically over time. To understand the source of differences between illiterates' and literates' processing it is vital to understand what processes unfold and when. It goes without saying that (as all methods) online and neuroimaging methods have their own limitations. Converging evidence from a variety of techniques is therefore important. A close look at the reviewed research also reveals substantial gaps in some areas of inquiry. For instance, there is almost no research on the effect of formal literacy on syntactic processing.

Reading as a recent cultural invention has not been shaped by evolutionary processes and thus must make use of cognitive systems and cortical networks which are either domain-general or have evolved for other purposes (cf. Dehaene \& Cohen, 2007). Research on the effect of literacy thus is a powerful tool to investigate how cultural inventions impact on cognition and brain functioning. We expect therefore that research on literacy-on-cognition effects will become more and more influential in coming years. A useful way forward will be longitudinal studies. Even the best-controlled cross-sectional study will attract criticisms about potential crucial differences between the illiterates, ex-illiterates, and/or literates compared. Longitudinal studies involving reading instruction and assessment before, during, and after reading instruction has been completed are likely to provide strong and direct evidence of the effect of literacy on cognitive processing.

Our review shows that effects of literacy are clearly beneficial rather than detrimental but simply for the reason that we live in literate societies and literacy confers important advantages for functioning in a literate society. The more (highly) literate a society is (and by extension the demands of society for literacy skills), the more advantages (high) literacy will confer. It should go without saying that this does not mean that illiterates and low literates are in any way deficient as human beings. They just haven't obtained a skill that is in high demand and highly valued by large parts of society. Nevertheless, we believe more efforts have to be spent on educating policy makers about the effect of literacy on the mind. Literacy rates are to a large extent determined by the priorities of a society, for example, by how much effort a society is willing to focus on eradicating literacy, or the financial resources it is willing to allocate to teach reading and writing. Investments of the economic returns of developing countries in education are often delayed and frequently fail to reach the poorest groups of society. Moreover, progress is often impeded by entrenched hierarchical social divisions and cultural factors. Another factor is the perception that educational attainment and job opportunities are not closely linked which often decreases the motivation of illiterates to take part in literacy programs. In short, literacy remains an important barrier to individual and national development in large parts of the world. Literacy empowers individuals, and by extension nations, to achieve their potential and goals. Movement of people in a globalised world has also resulted into movement of people with low literacy levels around the globe. Low educated immigrants in many countries increase the great social relevance of literacy research (Young-Scholten, 2013). Education policy and pedagogical support will not be efficacious or may even be misdirected without a detailed knowledge and awareness of the effects of literacy on cognitive functioning. 


\section{Short Biography}

Falk Huettig is a Senior Investigator at the Max Planck Institute for Psycholinguistics in Nijmegen, Netherlands and a Visiting Professor at the University of Hyderabad, India. He received a PhD in psychology from the University of York, UK. His research focuses on the effect of cultural inventions such as reading on general cognition in children, illiterate adults, and individuals with reading impairments. Other main interests include language-vision interactions and predictive language processing.

Ramesh Kumar Mishra is an Associate Professor at the Centre for Neural and Cognitive Sciences at the University of Hyderabad, India. He received a $\mathrm{PhD}$ in linguistics from the Jawaharlal Nehru University Delhi. His main interests are language and cognitive control in bilinguals, the influence of literacy on language-vision interactions and the interplay of language and attention.

\footnotetext{
Notes

* Correspondence to: Falk Huettig, Max Planck Institute for Psycholinguistics, PO Box 310, 6500 AH Nijmegen, The Netherlands. E-mail: falk.huettig@mpi.nl

1 An interesting anecdote is that the KGB was very alarmed when they intercepted Luria's telegram to Vygotsky because they interpreted 'The Uzbekis have no illusions' as meaning that the Uzbek people had no illusions about Soviet rule (Nell, 1999).
}

\section{Works Cited}

Adrian, J. A., J. Alegria, and J. Morais. 1995. Metaphonological abilities of Spanish illiterate adults. International Journal of Psychology 30. 329-353.

Allik, J. 2013. Do primitive people have illusions? Dubna Psychological Journal 3. 40-42.

Altmann, G. T. M., and Y. Kamide. 1999. Incremental interpretation at verbs: restricting the domain of subsequent reference. Cognition 73. 247-264.

Anthony, J. L., and D. J. Francis. 2005. Development of phonological awareness. Current Directions in Psychological Science 14(5). 255-259.

Anthony, J. L., and C. J. Lonigan. 2004. The nature of phonological awareness: converging evidence from four studies of preschool and early grade school children. Journal of Educational Psychology 96(1). 43-55.

Ardila, A., M. Rosselli, and P. Rosas. 1989. Neuropsychological assessment in illiterates: visuopatial and memory abilities. Brain and Cognition 11. 147-166.

Arnett, J. 2008. The neglected 95\%: why American psychology needs to become less American. American Psychologist 63. 602-614.

Bengtsson, S. L., Z. Nagy, S. Skare, L. Forsman, H. Forssberg, and F. Ullén. 2005. Extensive piano practicing has regionally specific effects on white matter development. Nature Neuroscience 8(9). 1148-1150.

Bolger, D. J., C. A. Perfetti, and W. Schneider. 2005. Cross-cultural effect on the brain revisited: universal structures plus writing system variation. Human brain mapping 25(1). 92-104.

Bramão, I., A. Mendonça, L. Faísca, M. Ingvar, K. M. Petersson, and A. Reis. 2007. The impact of reading and writing skills on a visuo-motor integration task: a comparison between illiterate and literate subjects. Journal of the International Neuropsychological Society 13(2). 359-364.

Breivik, P. S. 1991. A signal for the need to restructure the learning process. NASSP Bulletin 75(535). 1-8.

Brucki, S. M. D., and R. Nitrini. 2008. Cancellation task in very low educated people. Archives of Clinical Neuropsychology 23. 139-147.

Carreiras, M., M. Seghier, S. Baquero, A. Estévez, A. Lozano, J. T. Devlin, and C. J. Price. 2009. An anatomical signature for literacy. Nature 461. 983-988.

Castro-Caldas, A., P. Cavaleiro Miranda, I. Carmo, R. Reis, L. Leote, C. Ribeiro, and E. Ducla-Soares. 1999. Influence of learning to read and write on the morphology of the corpus callosum. European Journal of Neurology 6. 23-28.

Castro-Caldas, A., K. M. Petersson, A. Reis, S. Stone-Elander, and M. Ingvar. 1998. The illiterate brain. Learning to read and write during childhood influences the functional organization of the adult brain. Brain 121. 1053-1063. 
Chatterjee, A. 2001. Language and space: some interactions. Trends in Cognitive Sciences 5. 55-61.

Cohen, L., S. Dehaene, L. Naccache, S. Lehéricy, G. Dehaene-Lambertz, M. A. Hénaff, and F. Michel. 2000. The visual word form area spatial and temporal characterization of an initial stage of reading in normal subjects and posterior splitbrain patients. Brain 123(2), 291-307.

Coltheart, M. 2006. Perhaps functional neuroimaging has not told us anything about the mind (so far). Cortex 42(3). $422-427$.

Corballis, M. C., and I. L. Beale. 1976. The psychology of left and right. Hillsdale, NJ: Erlbaum.

Da Silva, C., K. M. Petersson, L. Faísca, M. Ingvar, and A. Reis. 2004. The effects of literacy and education on the quantitative and qualitative aspects of semantic verbal fluency. Journal of Clinical and Experimental Neuropsychology 26(2). $266-277$.

Dehaene, S., and L. Cohen (2007). Cultural recycling of cortical maps. Neuron 56(2). 384-398.

Dehaene, S., F. Pegado, L. W. Braga, P. Ventura, G. N. Filho, A. Jobert, G. Dehaene-Lambertz, R. Kolinsky, J. Morais, and L. Cohen. 2010. How learning to read changes the cortical networks for vision and language. Science 330. 1359-1364.

DeLong, K., T. Urbach, and M. Kutas. 2005. Probabilistic word pre-activation during language comprehension inferred from electrical brain activity. Nature Neuroscience 8(8). 1117-1121.

Dobel, C., G. Diesendruck, and J. Bölte. 2007. How writing system and Age influence spatial representations of actions a developmental, cross-linguistic study. Psychological Science 18(6). 487-491.

Ekman, P., and V. W. Friesen. 1975. Unmasking the face. Englewood Cliffs, NJ: Prentice hall.

Eviatar, Z. 1995. Reading direction and attention-effects on lateralized ignoring. Brain and Cognition 29(2). $137-150$.

—. 1997. Language experience and right hemisphere tasks: the effects of scanning habits and multilingualism. Brain and Language 58(1). 157-173.

. 2000. Culture and brain organization. Brain and Cognition 42. 50-52.

Federmeier, K. D., and M. Kutas. 1999. A rose by any other name: long-term memory structure and sentence processing. Journal of Memory and Language 41. 469-495.

C.Gallup. 2001. "- http://www.gallup.com/poll/16915/three-four-americans-believe-paranormal.aspx

Goody, J. 1987. The interface between the oral and the written. Cambridge, UK: Cambridge University Press.

Goody, J., and I. Watt. 1968. The consequences of literacy. In Literacy in traditional societies, ed. by J. Goody. Cambridge: Cambridge University Press.

Gross, C. G., and M. H. Bornstein. 1978. Left and right in science and art. Leonardo 11. 29-38.

Gutiérrez, R., D. Boison, U. Heinemann, and W. Stoffel. 1995. Decompaction of CNS myelin leads to a reduction of the conduction velocity of action potentials in optic nerve. Neuroscience letters 195(2). 93-96.

Havelock, E. 1963. Preface to Plato. Cambridge: Cambridge University Press. 1976. Origins of Western literacy. Toronto: OISE Press.

Henrich, J., S. J. Heine, and A. Norenzayan. 2010. The weirdest people in the world? Behavioral and Brain Sciences 33. 61-135.

Huettig, F., and J. M. McQueen. 2007. The tug of war between phonological, semantic, and shape information in languagemediated visual search. Journal of Memory and Language 54. 460-482.

Huettig, F., R. K. Mishra, U. Kumar, J. P. Singh, A. Guleria, V. Tripathi. 2013. (in preparation). Literacy and its cognitive characteristics - evidence from a North Indian rural community.

Huettig, F., J. Rommers, and A. S. Meyer. 2011a. Using the visual world paradigm to study language processing: a review and critical evaluation. Acta psychologica 137(2). 151-171.

Huettig, F., N. Singh, and R. K. Mishra. 2011b. Language-mediated visual orienting behavior in low and high literates. Frontiers in psychology 2. 285.

James, W. 1890. The principles of psychology, Vol. 1. New York: Dover Publications.

Jewell, G., and M. E. McCourt. 2000. Pseudoneglect: a review and meta-analysis of performance factors in line bisection tasks. Neuropsychologia 38(1), 93-110.

Kail, R., and T. A. Salthouse. 1994. Processing speed as a mental capacity. Acta psychologica 86(2). 199-225.

Kamide, Y., C. Scheepers, and G. T. M. Altmann. 2003. Integration of syntactic and semantic information in predictive processing: cross-linguistic evidence from German and English. Journal of Psycholinguistic Research 32. $37-55$.

Kimura, D. 1966. Dual functional asymmetry of the brain in visual perception. Neuropsychologia 4(3): 275-285.

Kolinsky, R., A. Verhaeghe, T. Fernandes, E. J. Mengarda, L. Grimm-Cabral, and J. Morais. 2011. Enantiomorphy through the looking glass: literacy effects on mirror-image discrimination. Journal of Experimental Psychology: General 140(2). 210.

Kosmidis, M. K., K. Tsapkini, V. Folia, C. Vlahou and G. Kiosseoglou. 2004. Semantic and phonological processing in illiteracy. Journal of the International Neuropsychological Society 10(6). 818-827.

Lachmann, T., G. Khera, N. Srinivasan, and C. Van Leeuwen. 2012. Learning to read aligns visual analytical skills with grapheme-phoneme mapping: evidence from illiterates. Frontiers in evolutionary neuroscience 4.8.

Landau, A. N., and P. Fries. 2012. Attention samples stimuli rhythmically. Current biology 22(11). 1000-1004.

Lamdan, E. 2013. Who had illusions? Alexander R. Luria's Central Asian experiments on optical illusions. Dubna Psychological Journal 3. 66-76. 
Lévi-Bruhl, L. 1923. Primitive mentality. London: George Allen \& Unwin.

Levi-Strauss, C. 1961. Tristes tropiques. New York: Atheneum, cited in Olson.

Lukatela, K., C. Carello, D. Shankweiler, and I. Y. Liberman. 1995. Phonological awareness in illiterates: observations from Serbo-Croatian. Applied Psycholinguistics 16. 463-487.

Luria, A. R. 1934. The second psychological expedition to Central Asia. Pedagogical Seminary and Journal of Genetic Psychology 44. $255-259$.

Luria, A. 1976. Cognitive development: its cultural and social foundations. Cambridge: Cambridge University Press.

Maass, A., and A. Russo. 2003. Directional bias in the mental representation of spatial events: nature or culture? Psychological Science 14. 296-301.

Manly, J. J., D. M. Jacobs, M. Sano, K. Bell, C. A. Merchant, S. A. Small, and Y. Stern. 1999. Effect of literacy on neuropsychological test performance in nondemented, education-matched elders. Journal of the International Neuropsychological Society 5. 191-202.

Mani, N., and F. Huettig(2012). Prediction during language processing is a piece of cake - but only for skilled producers. Journal of Experimental Psychology: Human Perception and Performance 38. 843-847.

Matute, E., F. Leal, D. Zarabozo, A. Robles, and C. Cedillo. 2000. Does literacy have an effect on stick construction tasks? Journal of the International Neuropsychological Society 6. 668-672.

Mishra, R. K., N. Singh, A. Pandey, and F. Huettig. 2012. Spoken language-mediated anticipatory eye movements are modulated by reading ability: evidence from Indian low and high literates. Journal of Eye Movement Research 5(1). 1-10.

Morais, J., P. Bertelson, L. Cary, and J. Alegria. 1986. Literacy training and speech analysis. Cognition 24. 45-64.

Morais, J., S.- L. Castro, and R. Kolinsky. 1991. La reconnaissance des mots chez les adultes illettre's. In La reconnaissance des mots dans les diffe'rentes modalite's sensorielles. Etudes de psycholinguistique cognitive, ed. by R. Kolinsky, J. Morais and J. Segui, 59-80. Paris: Presses Universitaires de France.

Morais, J., L. Cary, Alegria, J., and P. Bertelson. 1979. Does awareness of speech as a sequence of phones arise spontaneously? Cognition 7. 323-331.

McLuhan, M. 1962. The Gutenberg galaxy. Toronto: University of Toronto Press.

Nell, V. 1999. Luria in Uzbekistan: the vicissitudes of cross-cultural neuropsychology. Neuropsychology review 9(1). 45-52.

Nestor, A., M. Behrmann, and D. C. Plaut. 2013. The neural basis of visual word form processing: a multivariate investigation. Cerebral Cortex, 23(7), 1673-1684.

Nicholls, M. E., and G. R. Roberts. 2002. Can free-viewing perceptual asymmetries be explained by scanning, pre-motor or attentional biases? Cortex 38(2). 113-136.

Olivers, C. N. L., F. Huettig, J. P. Singh, and R. K. Mishra. (2014). The influence of literacy on visual search. Visual Cognition, 21, 74-101.

Olson, D. R. (1994). The world on paper: the conceptual and cognitive implications of writing and reading. Cambridge: Cambridge University Press.

Olson, D. R., and N. Torrance. 1991. Literacy and orality. Cambridge University Press.

Ong, W.. 1982. Orality and literacy: the technologizing of the word. London: Methuen.

Orihuela, K. B., M. Carreiras, and J. A. Dunabeita. 2013. Does literacy change face recognition? Poster presented at 54 th Annual Meeting of the Psychonomic Society, Toronto, November.

Ostrosky-Solís, F., M. A. García, and M. Pérez. 2004. Can learning to read and write change the brain organization? An electrophysiological study. International Journal of Psychology 39(1), 27-35.

Page, M. 2006. What can't functional neuroimaging tell the cognitive psychologist?. Cortex 42(3). 428-443.

Padakannaya, P., M. L. Devi, B. Zaveria, S. K. Chengappa, and J. Vaid. 2002. Directional scanning effect and strength of reading habit in picture naming and recall. Brain \& Cognition 48(2/3). 484-490.

Pattanayak, D. P. 1991. Literacy: an instrument of oppression. In (Eds.) Literacy and orality, ed. by D. R. Olson and N. Torrance, 105-108. Cambridge: Cambridge University Press.

Petersson, K. M., and A. Reis. 2006. Characteristics of illiterate and literate cognitive processing: implications of brainbehavior co-constructivism. In Lifespan development and the brain: the perspective of biocultural co-constructivism, ed. by P. B. Baltes, P. Reuter-Lorenz and F. Rösler, 279-305. Cambridge, UK: Cambridge University Press.

Petersson, K. M., A. Reis, S. Askelof, A. Castro-Caldas, and M. Ingvar. 2000. Language processing modulated by literacy: a network analysis of verbal repetition in literate and illiterate subjects. Journal of Cognitive Neuroscience 12(3). 364-382.

Petersson, K. M., C. Silva, A. Castro-Caldas, M. Ingvar, and A. Reis. 2007. Literacy: a cultural influence on functional leftright differences in the inferior parietal cortex. European Journal of Neuroscience 26(3). 791-799.

Pezzulo, G., R. Falcone, and J. Hoffmann. 2007. Anticipation and anticipatory behavior. Cognitive Processing 8(2). 67-70.

Popper, K. 2002. The logic of scientific discovery. Routledge. London.

Prakash, P., D. Rekha, R. Nigam, and Karanth, P. 1993. Phonological awareness, orthography and literacy. In Literacy and language analysis, ed. by R. Scholes, 55-70. Hillsdale, NJ: Lawrence Erlbaum.

Price, C. J., and J. T. Devlin. 2003. The myth of the visual word form area. Neuroimage 19(3). 473-481.

Random House Kermerman Webster's College Dictionary. 2010. Random house reference.

-.. 1986. The ability to manipulate speech sounds depends on knowing alphabetic writing. Cognition 24. 31-44. 
Reis, A., and A. Castro-Caldas. 1997. Illiteracy: a bias for cognitive development. Journal of the International Neuropsychological Society 3. 444-450.

Reis, A., L. Faísca, M. Ingvar, and K. M. Petersson. 2006. Color makes a difference: two-dimensional object naming in literate and illiterate subjects. Brain and Cognition 60. 49-54.

Reis, A., M. Guerreiro, C. Garcia, and A. Castro- Caldas. 1995. How does an illiterate subject process the lexical component of arithmetics? Journal of the International Neuropsychological Society 1. 206.

Reis, A., M. Guerreiro, and K. M. Petersson. 2003. A sociodemographic and neuropsychological characterization of an illiterate population. Applied Neuropsychology 10(4). 191-204.

Reis, A., and K. M. Petersson. 2003. Educational level, socioeconomic status and aphasia research: a comment on Connor et al. (2001) - effect of socioeconomic status on aphasia severity and recovery. Brain and Language 87. 449-452.

Reis, A., K. M. Petersson, A. Castro-Caldas, and M. Ingvar. 2001. Formal schooling influences two- but not threedimensional naming skills. Brain and Cognition, 47. 397-411.

Rivers, W. H. R. 1905. Observations on the sense of the Todas. British Journal of Psychology 1. 321-396.

Rommers, J., A. S. Meyer, P. Praamstra, and F. Huettig. 2012. The contents of predictions in sentence comprehension: activation of the shape of objects before they are referred to. Neuropsychologia 51(3). 437-447.

Rogers, H. 1995. Optimal orthographies (pp. 31-43). In Scripts and literacy,ed. by I. Taylor, D. R. Olson. Dordrecht, Netherlands: Kluwer Academic Publishers.

Salthouse, T. A. 1996. The processing-speed theory of adult age differences in cognition. Psychological review 103(3). 403-428. Scribner, S., and M. Cole. 1981. The psychology of literacy. Cambridge, MA: Harvard University Press.

Serniclaes, W., P. Ventura, J. Morais, and R. Kolinsky. 2005. Categorial perception of speech sounds in illiterate adults. Cognition 98. 835-844.

Smith, A., P. Monaghan, and F. Huettig. 2013a. Modelling the effects of formal literacy training on language mediated visual attention. In Proceedings of the 35th Annual Meeting of the Cognitive Science Society (CogSci 2013), ed. by M. Knauff, M. Pauen, N. Sebanz, and I. Wachsmuth, 3420-3425. Austin, TX: Cognitive Science Society. . 2013b. ${ }^{2}$. An amodal shared resource model of language-mediated visual attention Frontiers in Psychology, 4: 528.

Troyer, A. K., M. Moscovitch, and G. Winocur. 1997. Clustering and switching as two components of verbal fluency: evidence from younger and older healthy adults. Neuropsychology 11(1). 138.

.UNESCO. 2008. International literacy statistics: a review of concepts, methodology, and current data. Montreal: UNESCO.

Uttal, W. R. (2001). The new phrenology: the limits of localizing cognitive processes in the brain. The MIT Press.

Vaid J., M. Singh, T. Sakhuja, and G. C. Gupta. 2002. Stroke direction asymmetry in figure drawing: influence of handedness and reading/writing habits. Brain and Cognition 48. 597-602.

Vandenberghe, R., C. Price, R. Wise, O. Josephs, and R. S. Frackowiak. 1996. Functional anatomy of a common semantic system for word and pictures. Nature 383. 254-256.

Van Berkum, J. J. A., C. M. Brown, P. Zwitserlood, V. Kooijman, and P. Hagoort. 2005. Anticipating upcoming words in discourse: evidence from ERPs and reading times. Journal of. Experimental Psychology: Learning, Memory, E Cognition 31. 443-467.

Van Leeuwen, C., and T. Lachmann. 2004. Negative and positive congruence effects in letters and shapes. Perception E Psychophysics 66(6). 908-925.

Vul, E., C. Harris, P. Winkielman, and H. Pashler. 2009. Puzzlingly high correlations in fMRI studies of emotion, personality, and social cognition. Perspectives on psychological science 4(3). 274-290.

Vygotsky, L. S. 1978. Mind in society: the development of higher psychological processes society, ed. by M. Cole, V. John-Steiner, S. Scribner and E. Souberman. Cambridge: Harvard University Press.

Wicha, N. Y. Y., E. M. Moreno, and M. Kutas. 2004. Anticipating words and their gender: an event-related brain potential study of semantic integration, gender expectancy, and gender agreement in Spanish sentence reading. Journal of Cognitive Neuroscience 16. 1272-1288.

Wright, N. D., A. Mechelli, U. Noppeney, D. J. Veltman, S. A. Rombouts, J. Glensman, and C. J. Price. 2008. Selective activation around the left occipito-temporal sulcus for words relative to pictures: individual variability or false positives? Human brain mapping 29(8). 986-1000.

Young-Scholten, M. 2013. Low-educated immigrants and the social relevance of second language acquisition research. Second Language Research 29(4). 441-454.

Ziegler, J. C., and U. Goswami. 2005. Reading acquisition, developmental dyslexia, and skilled reading across languages: a psycholinguistic grain size theory. Psychological bulletin 131(1). 3-29 